\title{
SERS, XPS and DFT Study of Xanthine Adsorbed on Citrate-Stabilized Gold Nanoparticles
}

\author{
Stefano Caporali ${ }^{1}\left(\mathbb{D}\right.$, Francesco Muniz-Miranda ${ }^{2,+}{ }^{(\mathbb{C}}$, Alfonso Pedone $^{2}(\mathbb{D})$ and \\ Maurizio Muniz-Miranda ${ }^{3, * \text { (D) }}$ \\ 1 Department of Industrial Engineering, University of Florence, Via S. Marta 3, 50139 Firenze, Italy; \\ stefano.caporali@unifi.it \\ 2 Department of Chemical and Geological Sciences, University of Modena and Reggio Emilia, Via Campi 103, \\ 41125 Modena, Italy; f.muniz-miranda@chimieparistech.psl.eu (F.M.-M.); alfonso.pedone@unimore.it (A.P.) \\ 3 Department of Chemistry "Ugo Schiff”, University of Florence, Via Lastruccia 3, 50019 Sesto Fiorentino, Italy \\ * Correspondence: maurizio.muniz@unifi.it; Tel.: +39-349-184-9350 \\ + Current address: Chimie ParisTech, PSL Research University, CNRS, Institute of Chemistry for Life and \\ Health Sciences, F-75005 Paris, France.
}

Received: 15 May 2019; Accepted: 13 June 2019; Published: 15 June 2019

check for updates

\begin{abstract}
We have studied the adsorption of xanthine, a nucleobase present in human tissue and fluids that is involved in important metabolic processes, on citrate-reduced gold colloidal nanoparticles by means of surface-enhanced Raman scattering (SERS), absorption, and X-ray photoelectron spectroscopy (XPS) measurements, along with density functional theory (DFT) calculations. The citrate anions stabilize the colloidal suspensions by strongly binding the gold nanoparticles. However, these anions do not impair the adsorption of xanthine on positively-charged active sites present on the metal surface. We have obtained the Fourier transform (FT)-SERS spectra of adsorbed xanthine by laser excitation in the near infrared spectral region, where interference due to fluorescence emission does not usually occur. In fact, the addition of chloride ions to the Au/xanthine colloid induces the aggregation of the gold nanoparticles, whose plasmonic band is shifted to the near infrared region where there is the exciting laser line of the FT-Raman instrument. Hence, this analytical approach is potentially suitable for spectroscopic determination of xanthine directly in body fluids, avoiding fluorescence phenomena induced by visible laser irradiation.
\end{abstract}

Keywords: SERS; XPS; DFT; gold nanoparticles; xanthine

\section{Introduction}

In the last decade, gold nanoparticles have attracted much attention in the field of nanotechnology due to their many chemical and biomedical applications in sensing, catalysis, drug delivery, imaging, and nonlinear optical processes [1-6]. This is due to their peculiar properties, which can be summarized as: (1) marked chemical and physical stability; (2) high biocompatibility; (3) efficient surface functionalization with organic and biological ligands; and (4) enhanced optical responses related to surface plasmons. In particular, the use of gold nanoparticles in diagnostics, especially for the detection of DNA/RNA chains and their nucleobases [7-9], is getting more and more interest. The most common procedure for obtaining stable aqueous suspensions of gold nanoparticles is the reduction of tetrachloroauric acid by sodium citrate $[10,11]$. The role of the citrate anions in the formation of nanosized gold particles has been the subject of experimental and theoretical studies [12,13]. However, the type of interactions between citrate and gold nanoparticles, as well the effect on the stabilization and reactivity of the particles, have not been clarified yet.

Xanthine is a nucleobase present in human tissue and fluids that is involved in metabolic processes. Identifying the presence of xanthine in human organisms is a quite important task, because high levels 
of this molecule provoke severe problems by forming kidney stones as occurs with uric acid [14,15]. Surface-enhanced Raman scattering (SERS) spectroscopy is a powerful sensoristic technique as it overcomes the scarce sensitivity of the normal Raman technique, where molecules are adsorbed on silver or gold nanostructured substrates, with huge enhancement factors with respect to the Raman response of the non-adsorbed molecules $[16,17]$. Here, we have studied the adsorption of xanthine on citrate-reduced gold colloidal nanoparticles by means of SERS and X-ray photoelectron spectroscopy (XPS) measurements, along with density functional theory (DFT) calculations. In particular, we have analyzed the role of the citrate anions regarding both the metallic colloidal substrate and the xanthine molecules adsorbed on gold. In fact, a strong adsorption of citrate anions on gold could provide a double effect by (1) ensuring a good stabilization of the gold colloidal suspensions due to the repulsion between the negative charges, also in the presence of adsorbed organic molecules and (2) favoring the adsorption of ligand molecules by promoting the formation of suitable active-sites on the surface of the metal nanoparticles. Hence, this study is also of particular importance to understand the SERS response of these nanomaterials, which is closely related to the adsorption of ligand molecules. Moreover, with added chloride anions we have obtained the SERS-activation of the $\mathrm{Au} /$ xanthine colloids in the near-infrared spectral region, where fluorescence usually does not occur. Hence, this analytical approach is potentially suitable for SERS determination of xanthine directly in body fluids, avoiding fluorescence phenomena induced by visible laser irradiation.

\section{Materials and Methods}

\subsection{Sample Preparation}

By following the Turkevich preparation method [10] with tetrachloroauric acid (Aldrich, purity 99.9\%) and sodium citrate (Aldrich, purity 99\%), gold nanoparticles in colloidal aqueous suspension ( $\mathrm{pH} \sim 6$ ) were obtained. Xanthine (Sigma, purity $\geq 99.5 \%$ ), purified by recrystallization, was added to the Au colloid ( $10^{-6} \mathrm{M}$ or $10^{-7} \mathrm{M}$ concentration). The addition of $\mathrm{NaCl}\left(10^{-3} \mathrm{M}\right.$ concentration) allowed observation of the Fourier transform (FT)-SERS spectra of xanthine.

\subsection{Raman Measurements}

FT-SERS spectra of Au/xanthine colloids in the Stokes spectral range of $50-3600 \mathrm{~cm}^{-1}$ were obtained with a Fourier transform (FT)-Raman spectrometer (Bruker Optics, Model MultiRam), a broad range quartz beam-splitter, an air-cooled Nd:YAG laser $(1064 \mathrm{~nm})$, and a Ge diode detector cooled with liquid nitrogen. The measurements were recorded in a $180^{\circ}$ geometry, with $200 \mathrm{~mW}$ of laser power.

\subsection{UV-Vis-NIR Absorption Measurements}

Absorption spectra of the gold colloidal suspensions were observed at room temperature in the 200-1100 $\mathrm{nm}$ region with a Cary 5 Varian spectrophotometer by using $2 \mathrm{~mm}$-optical pass quartz cuvettes.

\subsection{XPS Measurements}

Glass substrates with deposited Au colloidal nanoparticles were introduced in an ultrahigh vacuum (UHV; $2 \times 10^{-9}$ mbar) system equipped with a VSW HAC 5000 hemispherical electron energy analyzer and a non-monochromatic $\mathrm{Mg} \mathrm{K} \alpha$ X-ray source (1253.6 eV) through a loadlock under nitrogen flux, in order to minimize the exposure to air contaminants, and kept for at least $12 \mathrm{~h}$ before the measurements were taken. The XPS spectra, referenced to C 1s peak at $284.8 \mathrm{eV}$ attributed to adventitious carbon, were acquired in the constant-pass-energy mode at Epas $=44 \mathrm{eV}$ and fitted by means of CasaXPS software by adopting Gauss-Lorentz curves and subtraction of a Shirley-type background. 


\subsection{Computational Details}

All DFT calculations were carried out by means of the Gaussian 09 package [18], adopting the B3LYP hybrid exchange and correlation functional $[19,20]$ and LANL2DZ basis set [21-23]. The optimized geometries corresponded to true energy minima by considering that all vibrational frequencies were real and positive. The Raman intensities $\left(I_{i}\right)$ were obtained from the calculated activities $\left(A_{i}\right)$ by following the literature relationship [24,25]:

$$
I_{i}=\frac{f\left(v_{0}-v_{i}\right)^{4} A_{i}}{v_{i}\left(1-e^{-\frac{h c v_{i}}{k T}}\right)} .
$$

Here, $v_{0}$ and $v_{i}$ are the excitation frequency and the $i$ th vibrational frequency, respectively, expressed in $\mathrm{cm}^{-1}, h, c$ and $k$ are fundamental constants, and $f$ is a common normalization factor for all peak intensities.

\section{Results and Discussion}

\subsection{XPS Spectra}

XPS spectra characteristics of carbon and gold, collected on soda-glass supported gold colloidal nanoparticles, are displayed in Figures 1 and 2.

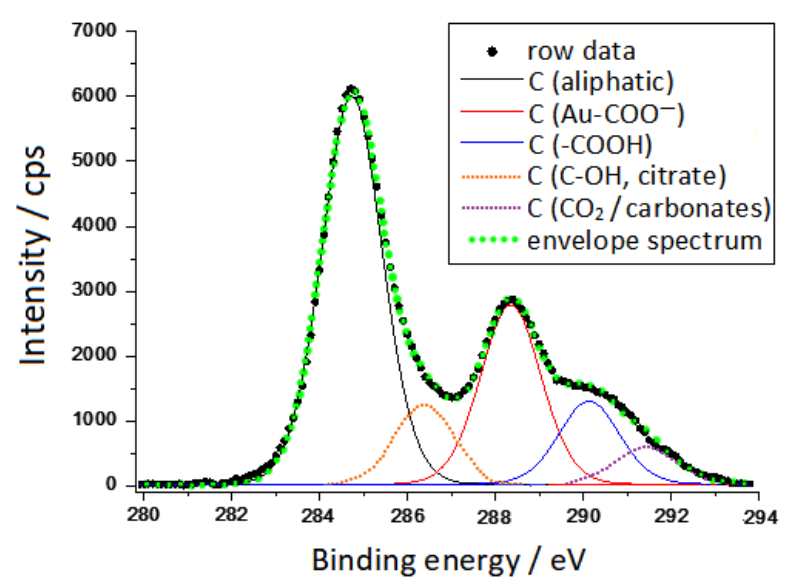

Figure 1. X-ray photoelectron spectroscopy (XPS) spectrum of deposited Au nanoparticles in the carbon 1 s spectral region.

The spectral region of carbon $1 \mathrm{~s}$ is complex and presents several constituents, at least 5 , which can be reasonably attributed as follows:

(1) $\mathrm{C}$ in aliphatic chains (deriving from atmospheric contamination and also from the $\mathrm{CH}_{2}$ group of citrates) at binding energy $(\mathrm{BE})=284.8 \mathrm{eV}$;

(2) $\mathrm{C}-\mathrm{OH}$ of citrate at $\mathrm{BE}=286.4 \mathrm{eV}$, according to the literature data [26];

(3) $\mathrm{COO}-\mathrm{Au}$ at $\mathrm{BE}=288.3 \mathrm{eV}$, whose binding energy is a little higher than that reported at $287.6 \mathrm{eV}$ by Park et al. [27];

(4) $\mathrm{COOH}$ (non-bonded to $\mathrm{Au}$ ) at $\mathrm{BE}=290.2 \mathrm{eV}$, analogously to what was reported by Park et al. [27];

(5) $\mathrm{C}$ in carbonates at $\mathrm{BE}=291.4 \mathrm{eV}$, according to the values $(291.3-291.8 \mathrm{eV}$ ) reported in the literature [28]. The presence of carbonates could result from the dissolution of $\mathrm{CO}_{2}$ in the aqueous solvent during the reduction process of gold ions with citrate. It is reasonable that this signal was not observed in the work of Park [27], because in that case the gold nanoparticles were washed with a thiol solution with the removal of the most soluble components. 


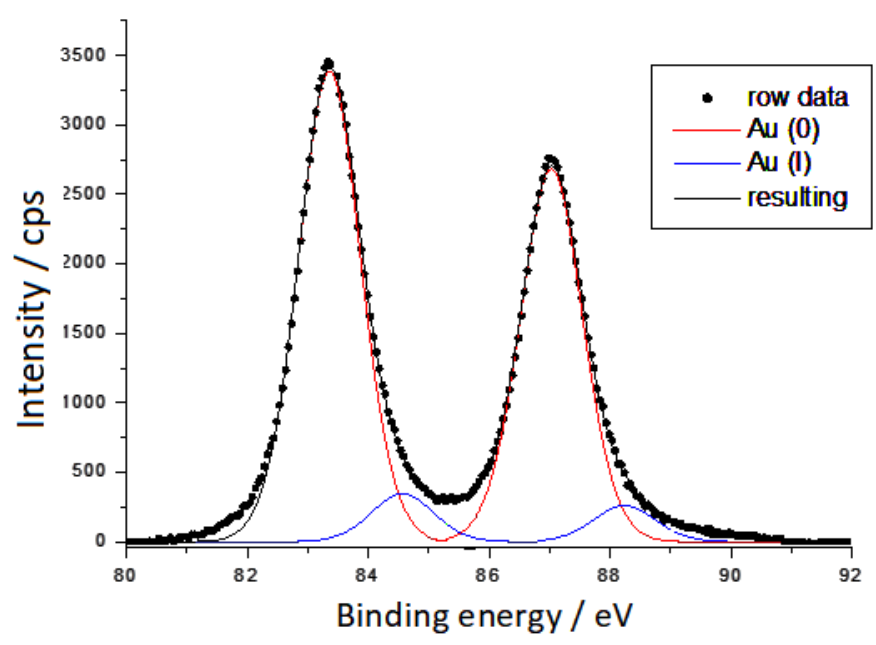

Figure 2. Au $4 \mathrm{f}$ doublet XPS spectral region of deposited Au nanoparticles.

However, the XPS spectrum relating to gold is simpler (see Figure 2), so it can be interpreted by only two components, after removing the glass contribution at $\mathrm{BE}=89.04 \mathrm{eV}$. The component at the lower $\mathrm{BE}(83.4 \mathrm{eV})$ is due to $\mathrm{Au}(0)$, whereas that at $\mathrm{BE}=84.5 \mathrm{eV}$ is due to $\mathrm{Au}(\mathrm{I})$. The peak relative to $\mathrm{Au}(0)$ occurs at a lower BE value than that usually found in nanosized metallic gold. For example, in gold nanoparticles obtained by laser ablation in pure water the peak due to $\mathrm{Au}(0)$ occurs at $\mathrm{BE}=84.3 \mathrm{eV}$, as shown in the Supplementary Materials (Figure S1). The shift observed in citrate-reduced gold nanoparticles cannot be related to instrumental calibration, because the BE values of carbon and glass ( $\mathrm{Si}$ and $\mathrm{O}$ ) well match those reported in the literature. In conclusion, the XPS spectra performed on gold nanoparticles show a large predominance of $\mathrm{Au}(0)$ strongly bound to citrate anions, which shift the binding energy of the metallic gold towards lower values, along with a smaller amount of $\mathrm{Au}(\mathrm{I})$.

Moreover, the presence of citrate anions linked to gold determines a negative zeta potential of the nanoparticles [29,30], preventing their aggregation and ensuring a marked stability in the aqueous suspension. In fact, even one year after the colloid preparation we did not observe any precipitate due to the collapse of metal nanoparticles.

\subsection{UV-Visible-NIR Absorption Spectra}

The adsorption of xanthine $\left(10^{-6} \mathrm{M}\right.$ concentration) on citrate-reduced Au nanocolloid induces only a small shift of the plasmonic band maximum from 530 to $535 \mathrm{~nm}$, without evidence of particle aggregation (see Figure 3). This means that the xanthine molecules do not replace the citrate ions, which remain bound to the metal surface, impairing particle aggregation due to the repulsion among the negative charges. Instead, for aggregation it is necessary to add $\mathrm{NaCl}\left(10^{-3} \mathrm{M}\right.$ concentration), which significantly increases the ionic strength of the aqueous suspension, promoting the formation of a secondary plasmonic band shifted to the near-infrared spectral region. Thus, it is possible to observe the SERS spectrum of xanthine by excitation in the near infrared (NIR) region, with a laser line at $1064 \mathrm{~nm}$ that is within the secondary plasmonic band, as shown in Figure 3. 


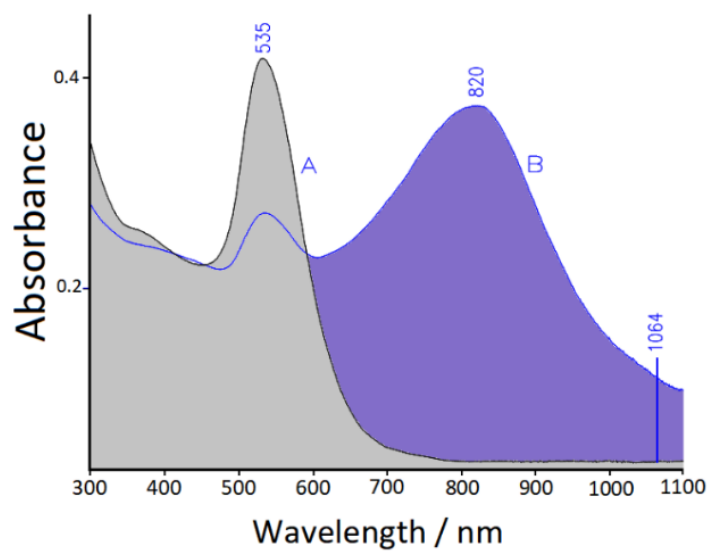

Figure 3. UV-vis-near infrared (NIR) extinction spectrum of Au colloids with $10^{-6} \mathrm{M}$ xanthine, before (A) and after (B) the addition of $10^{-3} \mathrm{M} \mathrm{NaCl}$. The $1064 \mathrm{~nm}$ excitation laser line is indicated.

\subsection{FT-SERS Spectra}

We have obtained FT-Raman spectra of xanthine adsorbed on Au colloidal nanoparticles by laser excitation in the near infrared (NIR) spectral region, where interference due to fluorescence does not generally occur. By excitation at $1064 \mathrm{~nm}$, no distinct SERS signal of xanthine $\left(10^{-6} \mathrm{M}\right.$ concentration) is detected, unless $\mathrm{NaCl}$ is added. Instead, in the presence of chloride anions ( $10^{-3} \mathrm{M}$ concentration), a strong FT-SERS spectrum is observed thanks to the plasmonic band shift towards the NIR region. This SERS spectrum, shown in Figure 4, is dominated by the most intense band at $658 \mathrm{~cm}^{-1}$, along with other intense bands at higher frequencies. The adopted concentration of xanthine in the gold colloids is quite low $\left(10^{-6} \mathrm{M}\right)$ in order to test the SERS efficiency with biological samples, where the presence of xanthine is relatively scarce. However, we have also obtained a SERS spectrum with $10^{-7} \mathrm{M}$ xanthine, as reported in the Supplementary Materials (Figure S2). This spectrum appears quite similar to that reported in Figure 4 with $10^{-6} \mathrm{M}$ xanthine, albeit weaker with increased noise. In the Supplementary Materials (Figure S3) the SERS spectrum $\left(10^{-6} \mathrm{M}\right)$ is compared with the Raman spectrum of xanthine in water solution at the same $\mathrm{pH}$ (around 6). Xanthine is barely soluble in water, so its concentration in solution is $10^{-3} \mathrm{M}$. By multiplying the Raman spectrum of xanthine by ten, comparable intensities are shown for both SERS and Raman bands. Hence, the adsorption of xanthine on citrate-reduced gold nanoparticles allows at least a Raman enhancement of four orders of magnitude to be obtained.

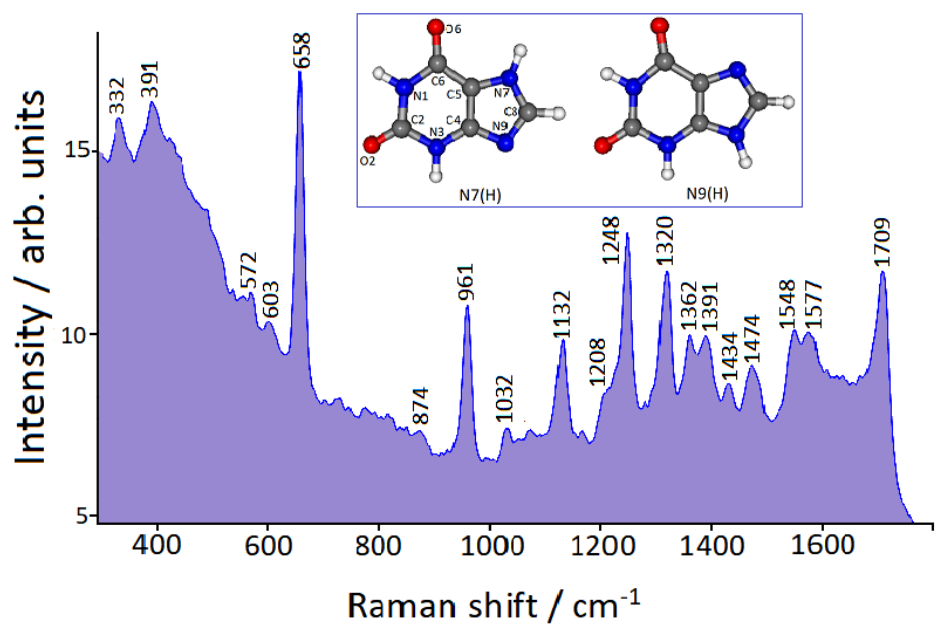

Figure 4. Fourier transform-surface-enhanced Raman scattering (FT-SERS) spectrum of $10^{-6} \mathrm{M}$ xanthine in Au colloid (1064 nm exciting line). The tautomeric forms of xanthine are shown in the inset. 


\subsection{DFT Calculations}

For a complete interpretation of the SERS data, a DFT computational approach is necessary, because in solution xanthine is presumably present as a mixture of two tautomers, N7(H) and N9(H) [31,32], whose structures are reported in the inset of Figure 4. DFT calculations, concerning the structures of the metal/molecule complexes that are formed on nanostructured metal surfaces and their Raman response, allow the acquisition of a large amount of information on the adsorption of organic ligands, along with the provision of a correct vibrational assignment of the observed SERS bands [33-35]. In the case of xanthine adsorbed on gold nanoparticles, we could identify which tautomer binds to metal and by which molecular site, and what interaction is established between the molecule and the active sites of the metal surface, along with the characteristics of the latter. Therefore, we have taken into account the binding of both tautomers with gold through the lone-pairs of the $\mathrm{sp}^{2}$ nitrogen atoms of the imidazolic ring of xanthine, i.e., the N9 atom of the tautomer N7(H) and the N7 atom of the tautomer N9(H). These atoms can act as electron-donors in the formation of metal/molecule complexes. For the interaction with gold, $\mathrm{Au}^{\circ}$ or $\mathrm{Au}^{+}$were considered as metal active sites (adatoms), on the basis of the indications deriving from XPS spectra, which show the surface presence of $\mathrm{Au}(0)$ with a minority amount of $\mathrm{Au}(\mathrm{I})$. Observed and calculated frequencies are compared in Table 1, whereas the optimized structures of the four complexes taken into account are shown in Figure 5. From the DFT calculations, only the $\mathrm{N} 9(\mathrm{H})-\mathrm{Au}^{+}$complex is able to reproduce all the frequencies observed in the SERS spectrum. Instead, the complexes with $\mathrm{Au}(0)$ are completely unsuitable for predicting the SERS bands. In this regard, it should be noted that the interactions of xanthine with $\mathrm{Au}^{+}$provoke a much larger electronic charge-transfer from molecule to metal than the interactions with $\mathrm{Au}^{\circ}$, with shorter $\mathrm{N}$-Au bonds (see Figure 5). In particular, the N9(H)- $\mathrm{Au}^{+}$complex shows the strongest electronic charge-transfer, as reported in Table 1. Mulliken and Hirshfeld partial charges in the N7(H)- $\mathrm{Au}^{+}$and $\mathrm{N} 9(\mathrm{H})-\mathrm{Au}^{+}$complexes are reported in Table S1 of the Supplementary Materials. Finally, while the tautomer $\mathrm{N} 7(\mathrm{H})$ is more stable than the tautomer $\mathrm{N} 9(\mathrm{H})$, the latter bound to $\mathrm{Au}^{+}$results more stable than the corresponding complex of the tautomer N7(H) with $\mathrm{Au}^{+}$. This is due to the fact that in the $\mathrm{N} 9(\mathrm{H})-\mathrm{Au}^{+}$complex, in addition to the N7-Au bond, an interaction is also established with the vicinal oxygen atom, as shown in Figure 5.
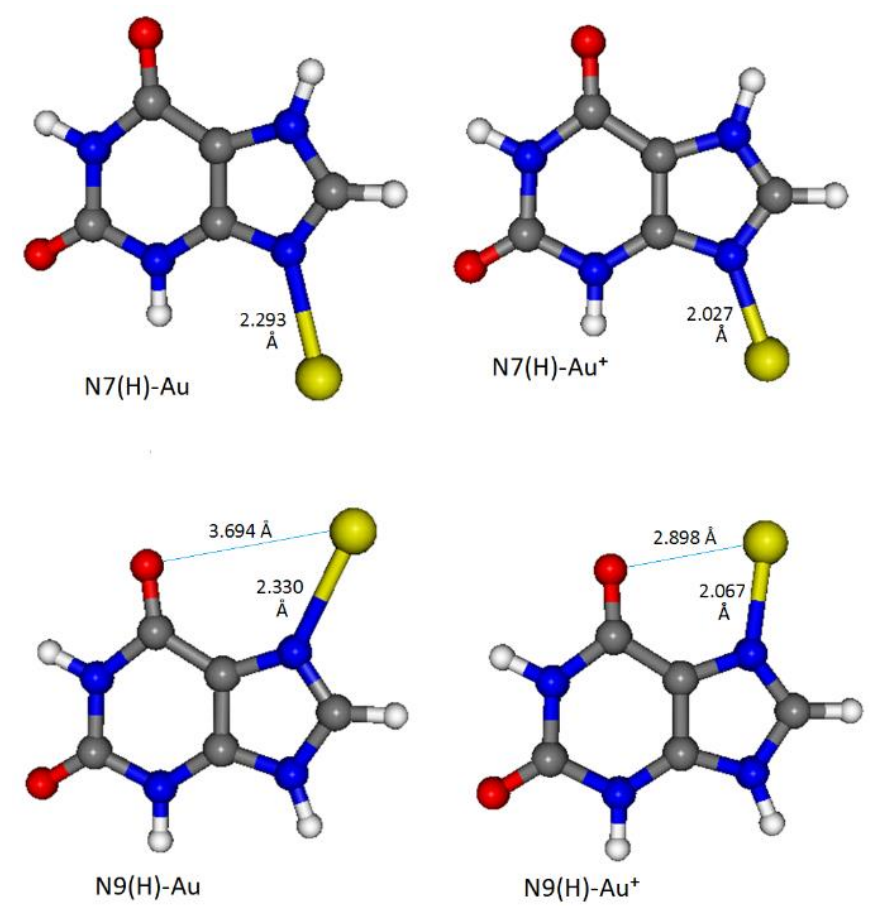

Figure 5. Density functional theory (DFT)-optimized structures of the xanthine/gold complexes. 
Table 1. Observed and calculated surface-enhanced Raman scattering (SERS) frequencies $\left(\mathrm{cm}^{-1}\right)$.

\begin{tabular}{|c|c|c|c|c|}
\hline $\begin{array}{l}\text { SERS on Au } \\
\text { Nanoparticles }\end{array}$ & $\begin{array}{c}\text { Calc. } \\
\text { N7(H)-Au }\end{array}$ & $\begin{array}{c}\text { Calc. } \\
\text { N9(H)-Au }\end{array}$ & $\begin{array}{c}\text { Calc. } \\
\text { N7(H)-Au }{ }^{+}\end{array}$ & $\begin{array}{c}\text { Calc. } \\
\text { N9(H)-Au }{ }^{+}\end{array}$ \\
\hline 332 & 342 & 332 & 344 & 352 \\
\hline 391 & 371 & 365 & 381 & 375 \\
\hline 572 & & 548 & 572 & 589 \\
\hline 603 & 613 & 611 & 619 & 617 \\
\hline 658 & 677 & 675 & 659 & 653 \\
\hline 874 & 873 & 841 & 855 & 857 \\
\hline 961 & 971 & 963 & 954 & 950 \\
\hline 1032 & & & 1013 & 1014 \\
\hline 1132 & 1121 & 1121 & 1130 & 1132 \\
\hline 1208 & 1207 & & 1218 & 1230 \\
\hline 1248 & 1270 & 1281 & 1269 & 1252 \\
\hline 1320 & 1310 & 1310 & 1334 & 1326 \\
\hline 1362 & 1322 & 1379 & & 1346 \\
\hline 1391 & 1408 & 1421 & 1415 & 1415 \\
\hline 1434 & 1422 & 1435 & 1433 & 1428 \\
\hline 1474 & 1464 & & 1464 & 1458 \\
\hline 1548 & & & 1502 & 1515 \\
\hline 1577 & 1584 & 1573 & 1591 & 1588 \\
\hline 1709 & 1712 & 1720 & 1720 & 1702 \\
\hline energy (a.u.) & -697.8012 & -697.7842 & -697.5511 & -697.5584 \\
\hline charge-transfer ${ }^{1}$ & $-0.1910 e$ & $-0.1763 e$ & $-0.3279 e$ & $-0.3544 e$ \\
\hline charge-transfer ${ }^{2}$ & $-0.1938 e$ & $-0.1916 e$ & $-0.5308 e$ & $-0.5361 e$ \\
\hline
\end{tabular}

A further indication concerning the adsorption of xanthine on gold can be deduced from the simulated SERS spectra of the complexes, as reported in Figure S4 of the Supplementary Materials: The $\mathrm{N} 9(\mathrm{H})-\mathrm{Au}^{+}$complex shows a SERS profile that better reproduces the experimental one with respect to that corresponding to the N7(H)-Au ${ }^{+}$complex.

Finally, on the basis of our DFT calculations, the correct assignment of the observed SERS bands is now possible, as shown in Figure 6. All the prominent SERS bands are in-plane deformations. In particular, the dominant SERS band at $658 \mathrm{~cm}^{-1}$ is attributable to the breathing vibration of the pyrimidinic ring of the molecule, whereas those at higher wavenumbers to deformations that involve ring bond stretching, $\mathrm{H}$-bending, and $\mathrm{C}=\mathrm{O}$ stretching modes. This assignment is important for identifying the "marker" SERS bands of xanthine in order to detect this nucleobase when other organic components are present in the sample. In particular, this analytical approach can be adopted to recognize xanthine in the presence of other purine nucleobases (adenine, guanine), which show a different spectral pattern. The SERS spectrum of adenine adsorbed on gold is dominated by a very strong band at $735 \mathrm{~cm}^{-1}[36,37]$, very far from the strongest SERS band of xanthine at $658 \mathrm{~cm}^{-1}$, without any spectral coincidence with the marker bands of xanthine at 961 and $1709 \mathrm{~cm}^{-1}$. It is also possible to distinguish the SERS spectrum of xanthine from that of guanine adsorbed on gold [38], even if SERS bands at 665, 958 and $1705 \mathrm{~cm}^{-1}$ are present in the latter, because the marker bands of xanthine at 1248 and $1320 \mathrm{~cm}^{-1}$ do not find correspondence in the SERS spectrum of guanine. A comparison between 
the marker SERS bands of xanthine, guanine, and adenine is shown in the Supplementary Materials (Table S2).
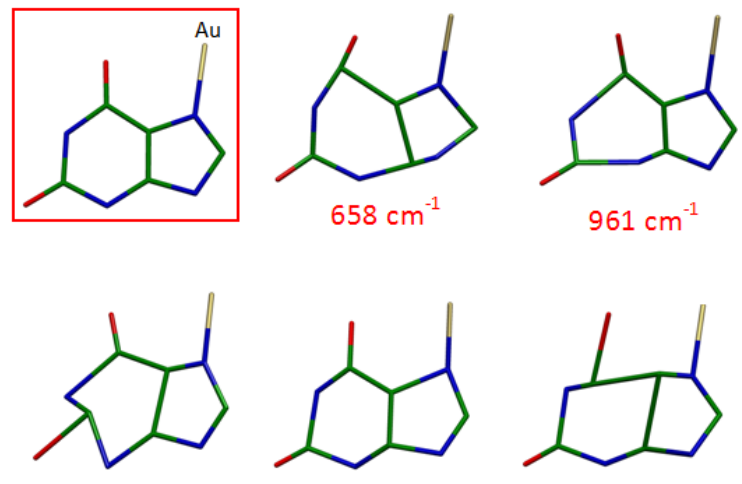

$1248 \mathrm{~cm}^{-1}$

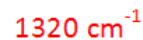

$1709 \mathrm{~cm}^{-1}$

Figure 6. Normal modes of the $\mathrm{N} 9(\mathrm{H})-\mathrm{Au}^{+}$complex, corresponding to the prominent SERS bands of xanthine adsorbed on gold.

\section{Conclusions}

The present study indicates that xanthine adsorbs on gold nanoparticles as tautomer $\mathrm{N}(9) \mathrm{H}$, linked to surface adatoms modelled as $\mathrm{Au}^{+}$in the DFT simulations. This conclusion is similar to that obtained from the adsorption of xanthine on Ag colloidal nanoparticles [39]. The citrate anions are strongly bound to metallic gold, as evidenced by the XPS measurements, but they allow the adsorption of ligand molecules. Indeed, these citrate anions impair the aggregation of the gold nanoparticles, also in the presence of adsorbed xanthine molecules, due to repulsion among the negative charges, and promote the formation of positively-charged active sites on the metal surface, which are able to bind the ligand molecules. The addition of chloride ions to the $\mathrm{Au} / \mathrm{xan}$ thine aqueous suspension promotes the aggregation of the gold nanoparticles, ensuring the observation of the FT-SERS spectrum by excitation in the NIR region, where fluorescence usually does not occur. Hence, this analytical approach is potentially suitable for SERS determination of xanthine directly in body fluids, avoiding spectral interference induced by visible laser irradiation. In actuality, fluorescence emission can be due to trace impurities that impair the observation of the Raman bands, as often occurs in biological samples [40]. Moreover, as the NIR region is coincident with the biological tissue transparency window [41], this could allow the use of SERS spectroscopy to recognize the presence of xanthine both in vitro and in vivo.

Finally, the identification of the marker SERS bands of xanthine could allow the spectroscopic recognition of this molecule in biological samples, where other components such as purine nucleobases are present.

Supplementary Materials: The following are available online at http://www.mdpi.com/1424-8220/19/12/2700/s1, Figures S1-S4, Tables S1 and S2.

Author Contributions: Conceptualization, F.M.-M. and M.M.-M.; methodology, F.M.-M. and M.M.-M; software, F.M.-M. and A.P.; investigation, F.M.-M., S.C., and M.M.-M.; resources, A.P., S.C., and M.M.-M.; data curation, F.M.-M., S.C., and M.M.-M.; writing—original draft preparation, F.M.-M., A.P., S.C., and M.M.-M.; writing-review and editing, M.M.-M.; supervision, M.M.-M.; project administration, A.P.; funding acquisition, A.P.

Funding: This work was supported by the Italian FIRB Project “Novel Multiscale Theoretical/Computational Strategies for the Design of Photo and Thermo responsive Hybrid Organic-Inorganic Components for Nanoelectronic Circuits".

Acknowledgments: The Italian “Ministero dell'Istruzione, dell'Università e della Ricerca" (MIUR) provided financial support to conduct this study.

Conflicts of Interest: The authors declare no conflict of interest. 


\section{References}

1. Dreaden, E.C.; Alkilany, A.M.; Huang, X.; Murphy, C.J.; El-Sayed, M.A. The golden age: Gold nanoparticles for biomedicine. Chem. Soc. Rev. 2012, 41, 2740-2779. [CrossRef] [PubMed]

2. Elahi, N.; Kamali, M.; Baghersad, M.H. Recent biomedical applications of gold nanoparticles: A review. Talanta 2018, 184, 537-556. [CrossRef] [PubMed]

3. Amendola, V.; Pilot, R.; Frasconi, M.; Maragò, O.M.; Iatì, M.A. Surface plasmon resonance in gold nanoparticles: A review. J. Phys. Condens. Matter 2017, 29, 203002. [CrossRef] [PubMed]

4. Alex, S.; Tiwari, A. Functionalized Gold Nanoparticles: Synthesis, Properties and Applications-A Review. J. Nanosci. Nanotechnol. 2015, 15, 1869-1894. [CrossRef] [PubMed]

5. Kong, F.-Y.; Zhang, J.-W.; Li, R.-F.; Wang, Z.-X.; Wang, W.-J.; Wang, W. Unique Roles of Gold Nanoparticles in Drug Delivery, Targeting and Imaging Applications. Molecules 2017, 22, 1445. [CrossRef]

6. Xiong, W.; Mazid, R.; Yap, L.W.; Li, X.; Cheng, W. Plasmonic caged gold nanorods for near-infrared light controlled drug delivery. Nanoscale 2014, 6, 14388-14393. [CrossRef]

7. Basu, S.; Jana, S.; Pande, S.; Pal, T. Interaction of DNA bases with silver nanoparticles: Assembly quantified through SPRS and SERS. J. Colloid Interface Sci. 2008, 321, 288-293. [CrossRef]

8. Hakimian, F.; Ghourchian, H.; Hashemi, A.S.; Arastoo, M.R.; Rad, M.B. Ultrasensitive optical biosensor for detection of miRNA-155 using positively charged Au nanoparticles. Sci. Rep. 2018, 8, 2943. [CrossRef]

9. Carnerero, J.M.; Sánchez-Coronilla, A.; Martín, E.I.; Jimenez-Ruiz, A.; Prado-Gotor, R. Quantification of nucleobases/gold nanoparticles interactions: Energetics of the interactions through apparent binding constants determination. Phys. Chem. Chem. Phys. 2017, 19, 22121-22128. [CrossRef]

10. Turkevich, J.; Stevenson, P.C.; Hillier, J. A Study of the nucleation and growth processes in the synthesis of colloidal gold. Discuss. Faraday Soc. 1951, 11, 55-75. [CrossRef]

11. Frens, G. Controlled Nucleation for the Regulation of the Particle Size in Monodisperse Gold Suspensions. Nat. Phys. Sci. (London) 1973, 241, 20-22. [CrossRef]

12. Kumar, S.; Gandhi, K.S.; Kumar, R. Modeling of Formation of Gold Nanoparticles by Citrate Method. Ind. Eng. Chem. Res. 2007, 46, 3128-3136. [CrossRef]

13. Ji, X.; Song, X.; Li, J.; Bai, Y.; Yang, W.; Peng, X. Size Control of Gold Nanocrystals in Citrate Reduction: The Third Role of Citrate. J. Am. Chem. Soc. 2007, 129, 13939-13948. [CrossRef] [PubMed]

14. Königsberger, E.; Wang, Z.; Seidel, J.; Wolf, G. Solubility and dissolution enthalpy of xanthine. J. Chem. Thermodyn. 2001, 33, 1-9. [CrossRef]

15. Ichida, K.; Amaya, Y.; Kamatani, N.; Nishino, T.; Hosoya, T.; Sakai, O. Identification of two mutations in human xanthine dehydrogenase gene responsible for classical type I xanthinuria. J. Clin. Investig. 1997, 99, 2391-2397. [CrossRef] [PubMed]

16. Schlücker, S. Surface Enhanced Raman Spectroscopy: Analytical, Biophysical and Life Science Applications; Wiley-VCH: Weinheim, Germany, 2011.

17. Procházka, M. Surface-Enhanced Raman Spectroscopy, Bioanalytical, Biomolecular and Medical Applications; Springer: Basel, Switzerland, 2016.

18. Frisch, M.J.; Trucks, G.W.; Schlegel, H.B.; Scuseria, G.E.; Robb, M.A.; Cheeseman, J.R.; Scalmani, G.; Barone, V.; Mennucci, B.; Petersson, G.A.; et al. Gaussian 09; Revision D.01; Gaussian, Inc.: Wallingford, CT, USA, 2009.

19. Becke, A.D. Density-functional thermochemistry III. The role of exact exchange. J. Chem. Phys. 1993, 98, 5648-5652. [CrossRef]

20. Lee, C.; Yang, W.; Parr, R.G. Development of the Colle-Salvetti correlation-energy formula into a functional of the electron density. Phys. Rev. B 1988, 37, 785-789. [CrossRef] [PubMed]

21. Hay, P.J.; Wadt, W.R. Ab initio effective core potentials for molecular calculations. Potentials for the transition metal atoms Sc to Hg. J. Chem. Phys. 1985, 82, 270-283. [CrossRef]

22. Wadt, W.R.; Hay, P.J. Ab initio effective core potentials for molecular calculations. Potentials for main group elements Na to Bi. J. Chem. Phys. 1985, 82, 284-298. [CrossRef]

23. Hay, P.J.; Wadt, W.R. Ab initio effective core potentials for molecular calculations. Potentials for $\mathrm{K}$ to $\mathrm{Au}$ including the outermost core orbitals. J. Chem. Phys. 1985, 82, 299-310. [CrossRef]

24. Keresztury, G.; Holly, S.; Besenyei, G.; Varga, J.; Wang, A.; Durig, J.R. Vibrational spectra of monothiocarbamates-II. IR and Raman spectra, vibrational assignment, conformational analysis and ab initio calculations of S-methyl-N,N-dimethylthiocarbamate. Spectrochim. Acta A 1993, 49, 2007-2026. [CrossRef] 
25. Keresztury, G. Handbook of Vibrational Spectroscopy; Chalmers, J.M., Griffiths, P.R., Eds.; Wiley \& Sons: Chichester, UK, 2002; Volume 1, pp. 71-87.

26. Tselesh, A.S. Anodic behaviour of tin in citrate solutions: The IR and XPS study on the composition of the passive layer. Thin Solid Films 2008, 516, 6253-6260. [CrossRef]

27. Park, J.-W.; Shumaker-Parry, J.S. Strong Resistance of Citrate Anions on Metal Nanoparticles to Desorption under Thiol Functionalization. ACS Nano 2015, 9, 1665-1682. [CrossRef] [PubMed]

28. Wagner, C.D.; Riggs, W.M.; Davis, L.E.; Moulder, J.F.; Muilenberg, G.E. Handbook of X-ray Photoelectron Spectroscopy; Perkin-Elmer Corporation: Eden Prairie, MN, USA, 1979.

29. Verma, H.N.; Singh, P.; Chavan, R.M. Gold nanoparticle: Synthesis and characterization. Vet. World 2014, 7, 72-77. [CrossRef]

30. Muangnapoh, T.; Sano, N.; Yusa, S.-I.; Viriya-Empikul, N.; Charinpanitkul, T. Facile strategy for stability control of gold nanoparticles synthesized by aqueous reduction method. Curr. Appl. Phys. 2010, 10, 708-714. [CrossRef]

31. Polat, T.; Yildırım, G. Investigation of solvent polarity effect on molecular structure and vibrational spectrum of xanthine with the aid of quantum chemical computations. Spectrochim. Acta Part A 2014, 123, 98-109. [CrossRef] [PubMed]

32. Kulikowska, E.; Kierdaszuk, B.; Shugar, D. Xanthine, xanthosine and its nucleotides: Solution structures of neutral and ionic forms, and relevance to substrate properties in various enzyme systems and metabolic pathways. Acta Biochim. Pol. 2004, 51, 493-531. [PubMed]

33. Pagliai, M.; Muniz-Miranda, F.; Schettino, V.; Muniz-Miranda, M. Competitive Solvation and Chemisorption in Silver Colloidal Suspensions. Progr. Colloid Polym. Sci. 2011, 139, 39-44. [CrossRef]

34. Muniz-Miranda, M.; Pergolese, B.; Muniz-Miranda, F.; Caporali, S. SERS effect from Pd surfaces coated with thin films of Ag colloidal nanoparticles. J. Alloys Compd. 2015, 615, S357-S360. [CrossRef]

35. Gellini, C.; Deepak, F.L.; Muniz-Miranda, M.; Caporali, S.; Muniz-Miranda, F.; Pedone, A.; Innocenti, C.; Sangregorio, C. Magneto-plasmonic colloidal nanoparticles obtained by laser ablation of nickel and silver targets in water. J. Phys. Chem. C 2017, 121, 3597-3606. [CrossRef]

36. Kundu, J.; Neumann, O.; Janesko, B.G.; Zhang, D.; Lal, S.; Barhoumi, A.; Scuseria, G.E.; Halas, N.J. Adenineand Adenosine Monophosphate (AMP)-Gold Binding Interactions Studied by Surface-Enhanced Raman and Infrared Spectroscopies. J. Phys. Chem. C 2009, 113, 14390-14397. [CrossRef]

37. Pagliai, M.; Caporali, S.; Muniz-Miranda, M.; Pratesi, G.; Schettino, V. SERS, XPS, and DFT Study of Adenine Adsorption on Silver and Gold Surfaces. J. Phys. Chem. Lett. 2012, 3, 242-245. [CrossRef] [PubMed]

38. Pergolese, B.; Bonifacio, A.; Bigotto, A. SERS studies of the adsorption of guanine derivatives on gold colloidal nanoparticles. Phys. Chem. Chem. Phys. 2005, 7, 3610-3613. [CrossRef] [PubMed]

39. Muniz-Miranda, F.; Pedone, A.; Muniz-Miranda, M. Raman and Computational Study on the Adsorption of Xanthine on Silver Nanocolloids. ACS Omega 2018, 3, 13530-13537. [CrossRef]

40. Chase, D.B. Fourier transform Raman spectroscopy. J. Am. Chem. Soc. 1986, 108, 7485-7488. [CrossRef] [PubMed]

41. Smith, A.M.; Mancini, M.C.; Nie, S. Bioimaging: Second window for in vivo imaging. Nat. Nanotechnol. 2009, 4, 710-711. [CrossRef]

(C) 2019 by the authors. Licensee MDPI, Basel, Switzerland. This article is an open access article distributed under the terms and conditions of the Creative Commons Attribution (CC BY) license (http://creativecommons.org/licenses/by/4.0/). 